\title{
Growth retardation and delayed puberty in children and adolescents with juvenile idiopathic arthritis
}

Wioleta Umławska1, Anna Prusek-Dudkiewicz ${ }^{2}$

\author{
${ }^{1}$ Department of Anthropology, University of Wrocław, Poland \\ ${ }^{2}$ Department of Social Nursing, Laboratory of Social Paediatrics, Wrocław School \\ of Medicine, Poland
}

Submitted: 7 July 2008

Accepted: 30 November 2008

Arch Med Sci 2010; 6, 1: 19-23

DOI 10.5114/aoms.2010.13501

Copyright (c) 2010 Termedia \& Banach

\author{
Corresponding author: \\ Wioleta Umławska, PhD \\ Department of Anthropology \\ University of Wrocław \\ 35 Kuźnicza \\ 50-138 Wrocław, Poland \\ Phone: +48 713752284 \\ Fax: +48713752697 \\ E-mail: \\ wilota@antropo.uni.wroc.pl
}

\begin{abstract}
Juvenile idiopathic arthritis (JIA) is the most common joint disorder in developing children. Juvenile idiopathic arthritis is difficult to diagnose and treat. In some patients, signs and symptoms can be frustratingly inconsistent, contradictory or idiosyncratic. Short stature in patients with JIA is usually due to reduced growth in the lower extremities, and only rarely due to reduced growth in the spinal column. In some studies, children with JIA were found to have infantile body proportions. Puberty is delayed in children with JIA. In children with chronic arthritic disorders, there is a strong correlation between the activity of the disease and the age of puberty. The main goals in reducing growth retardation in children with JIA are promoting timely remission and reducing the duration and dosage of corticosteroid treatment. It is important to regularly monitor physical development. Further improvements to the treatment protocol depend on continued interdisciplinary research involving paediatricians, rheumatologists and clinical anthropologists.
\end{abstract}

Key words: children, chronic disease, short stature, puberty, glucocorticosteroid therapy.

\section{Introduction}

Juvenile idiopathic arthritis (JIA) is the most common joint disorder in developing children [1]. The incidence of JIA is between 6 and 19 per 100,000 with a prevalence of about 1 in 1000. The condition is slightly more common in females [2].

Juvenile idiopathic arthritis is difficult to diagnose and treat. In some patients, signs and symptoms can be frustratingly inconsistent, contradictory or idiosyncratic. In JIA, the clinical picture and course of inflammation vary considerably, and are different than in inflammatory conditions of the joints in adults [3]. Furthermore, the symptoms differ from patient to patient, and also change over the course of the disease. There are few reliable serological manifestations.

The classification of diseases accompanied by joint inflammation has been frequently revised. According to the criteria proposed by the International League against Rheumatism, JIA refers to inflammation of the joints in persons under 16 years old that lasts for at least 6 weeks [1]. Clinically, JIA can be divided into seven subtypes [4]:

- systemic,

- persistent oligoarticular, 
- extended oligoarticular,

- polyarticular with positive rheumatoid factor (RF),

- polyarticular with negative rheumatoid factor (RF),

- psoriatic arthritis, and

- arthritis related to enthesitis.

The name juvenile idiopathic arthritis has replaced previously used names such as juvenile chronic arthritis (JCA), which had been proposed by the European League against Rheumatism, and juvenile rheumatoid arthritis (JRA), which had been proposed by the American College of Rheumatology $[5,6]$.

\section{Growth disturbance}

Juvenile idiopathic arthritis is characterized by chronic inflammation in various tissues of the body, and can affect joints, ligaments, muscles and internal organs. Over the long term, inflammation can cause stiffening and deformation of the affected joints, and can lead to significant growth retardation $[7,8]$. Growth retardation can result in severely reduced body stature, which is defined as body height in the lowest third percentile of the population, or body height more than two standard deviations below the mean for the population.

The proportion of children with JIA that are abnormally short ranges from 10 to $40 \%[9,10]$. Growth retardation is significantly more severe in children with the systemic subtype of the disease and in children in whom many joints are affected $[9,11]$. Growth retardation is also more severe in children with extensive joint damage than in children with early or moderate anatomical changes [7, 12].

Factors responsible for growth retardation in chronically ill children include frequent infections, primary and secondary malnutrition, long-term stress related to being chronically ill or handicapped, and side effects of therapy. It is often difficult to tell how much growth retardation can be attributed to the disease itself, and how much to the side effects of treatment [13].

Growth retardation in children with JIA is especially severe when auto-immunological activity has been elevated over a long period, which is associated with high levels of the pro-inflammatory cytokines IL-1, IL- 6 and TNF- $\alpha$ [7, 14]. These cytokines reduce secretion of growth hormone from the pituitary gland, and also act directly on the growth plates of the long bones $[15,16]$.

In laboratory experiments, IL-1 and TNF- $\alpha$ have been found to reduce proliferation and differentiation in chondrocytes in the growth plates, to induce death in chondrocytes, and to disrupt the synthesis of type II collagen and proteoglycans $[17,18]$.

Inflammation also hampers blood circulation in the affected joints, which limits the supply of oxygen and nutrients to the growth plates of the long bones. At first, there is an increase in the rate of bone formation in the vicinity of the affected joint. However, if auto-immunological activity persists for a long time, cell proliferation in the growth plates ceases before development is complete, and the length of the limbs is likely to be irreversibly affected [18]. Effective and timely treatment can preserve growth potential in children with JIA, thereby allowing bone growth to catch up $[8,10]$.

Short stature in patients with JIA is usually due to reduced growth in the lower extremities, and only rarely due to reduced growth in the spinal column $[19,20]$. In some studies, children with JIA were found to have infantile body proportions [12, 19]. In one study, however, no abnormalities in body proportions were found [9]. The authors reported that reduced subischial leg length did not affect body proportions in children with JIA because it was proportional to the general reduction in body stature.

In experiments on the level of physical development in children with JIA, not only was the length of the lower extremities significantly reduced, but the proportions of the chest were also affected [12]. Chest width and chest capacity were both reduced.

Children with JIA are more easily exhausted by physical exertion because they are generally less physically active and experience pain related to the disease [21]. The capacity for physical exertion was particularly reduced in children with an active form of the disease and in children with many affected joints. Because children with JIA are frequently less physically active, muscle development is affected, which further contributes to the abnormal construction of the chest [21].

Another factor that reduces growth in children with JIA is long-term treatment with corticosteroids, which is usually administered to children with the systemic and polyarticular forms of the disease. Corticosteroids are usually administered when other drugs fail to bring about remission of the disease $[6,10]$.

Corticosteroids affect growth in many ways. High levels of corticosteroids stimulate the release of somatostatin, inhibit the release of growth hormone, insulin growth factor-1 (IGF-1) and IGF binding protein, decrease the expression of receptors for growth hormone and IGF-1, and reduce the level of IGF binding protein [22]. High levels of corticosteroids can also reduce proliferation in growth plate chondrocytes by inhibiting the expression of receptors for growth hormone and IGF-1. Furthermore, corticosteroids interfere with normal bone development by increasing the level of proteolysis in nearby muscle tissue [23].

The effect of corticosteroids on growth has been confirmed in short-term and longitudinal studies. 
In studies carried out using knemometry, the rate of growth in the lower extremities was reduced in children treated with corticosteroids, as was metabolic turnover in the bone tissue [24].

In one study on children with JIA, long-term treatment with corticosteroids irreversibly reduced terminal body height, whereas treatment lasting less than one year had no effect. The effect did not depend on the dosage administered [7].

On the other hand, in a longitudinal study on pre-pubertal children with juvenile idiopathic arthritis who were treated with corticosteroids, growth rate was significantly reduced only during the first year of treatment, after which it increased. This was attributed to an improvement in the course of the disease, to the low dosages of corticosteroids used, and to the fact that the course of the disease was carefully monitored [11].

Final growth parameters are not always reduced in patients suffering from juvenile idiopathic arthritis. In some children, catch-up growth is possible when the disease is in remission or when corticosteroid treatment is interrupted. In this case, final growth parameters can approach and even reach normal levels. This is especially true for children that are younger, and thus have been suffering from the disease for a shorter time [25].

In one study on children with juvenile idiopathic arthritis, catch-up growth was reported in $70 \%$ of the subjects examined. On the other hand, growth retardation was irreversible in the other $30 \%$, in spite of the fact that these children did not differ from the others in terms of duration of the disease activity or the dosage of corticosteroids administered. This was attributed to differences in the genetic potential for growth among the subjects [25].

Not all studies have confirmed a connection between the degree of growth retardation and the dosage of corticosteroids administered. However, it is generally believed that prednisone at a dosage of $0.25 \mathrm{mg} / \mathrm{kg} /$ day can affect growth [7, 8, 14].

Another factor responsible for growth retardation is malnourishment, which is frequently seen in children with JIA. In some cases, malnourishment can be severe enough to induce cachexia [26-28].

Malnourishment in children with JIA is caused by many factors. High levels of pro-inflammatory cytokines can reduce energy uptake and metabolism, even if the patient is on an appropriate diet. Energy intake in children with JIA is negatively correlated with IL-1 production [26]. Malnourishment is also more common in children with inflammation of the maxillo-mandibular joint, and in children in whom the digestive tract is affected to the point that nutrient assimilation is reduced. Coeliac disease, for example, is about seven times more common in children with JIA than in the general population [29]. Many of the drugs used in treating the disease can also cause disturbances of the gastro-intestinal tract. This is particularly true for methotrexate [27].

\section{Delayed puberty}

Sexual development is also delayed in children with JIA. In children with chronic arthritic disorders, there is a strong correlation between the activity of the disease and the age of puberty [30-32]. In girls with JIA, menarche occurs almost two years later than in healthy children. In boys, puberty is delayed because testosterone production by the testicular Leydig cells is reduced [33].

On the other hand, in a study on twenty-four year old women who had suffered from JIA during childhood, menarche was found to have occurred on average at age 13, which is about the same age as in healthy individuals [34]. There was also no significant difference between the women and their healthy peers in terms of fertility, although fecundity was significantly reduced. The women had a higher incidence of gynaecological disorders, and were more likely to miscarry [34].

\section{Treatment goals and pharmaceutical agents}

The main goals in reducing growth retardation in children with JIA are promoting timely remission and reducing the duration and dosage of corticosteroid treatment. Clinical symptoms can be improved and inflammation can be controlled by administering intra-articular corticosteroids, methotrexate, immuno-suppressing drugs and biological agents $[3,6]$.

Long-acting corticosteroids such as triamcinolone (Hexatrione), Depo-Medrol and Diprophos can be injected directly into the affected joints in patients with chronic or recurrent inflammation [3]. No more than three or four doses should be injected into a single joint. This method is particularly useful in cases of oligoarticular arthritis because corticosteroids are administered locally, not systemically. This often reduces the risk of side effects associated with systemic treatment [35-38].

Methotrexate is a folic acid antagonist. In one study, methotrexate was administered to children under ten years old with either oligoarticular or polyarticular onset JIA [39]. The study group consisted solely of children who had not received corticosteroids during the previous year. After one year of treatment with methotrexate, the children were responding positively to treatment. The number of affected joints was reduced by half. Growth rate was significantly improved, and body height was higher in children who responded positively to treatment than in children who did not respond [39]. On the other hand, methotrexate was less effective in children with the systemic form of the disease [40]. 
Children receiving methotrexate may require folic acid supplements. The dosage of folic acid administered should be individually tailored to the patient's needs [41].

Etanercept and other TNF- $\alpha$ antagonists reduce inflammation and make it possible to use more conservative doses of corticosteroids [42, 43]. Etanercept has been found to improve the rate of growth in pre-pubertal and pubertal children [44]. Long-term studies are needed to confirm the benefits of TNF- $\alpha$ antagonists, and to determine the importance of negative side effects such as increased frequency of infectious disorders [45].

Infliximab is a monoclonal antibody that binds TNF- $\alpha$. Preliminary reports of small-scale studies have been promising, although full-scale randomized placebo-controlled studies are needed to confirm the effectiveness and safety of the drug [46].

Adalimumab is a human monoclonal antibody that binds TNF- $\alpha$, and has also been used to treat JIA. In a study on 171 patients between four and seventeen years old with oligoarticular JIA, adalimumab was administered alone or in combination with methotrexate. Adalimumab was found to be very effective and to have relatively few side effects such as headaches, respiratory tract infections, and pain and reddening at the site of injection [47].

Anakinra is an IL-6 receptor antagonist. Preliminary testing has indicated that it rapidly improves the clinical state and laboratory test results of children with systemic JIA, with noticeable positive effects after only two weeks of treatment $[46,48]$.

Tocilizumab is another IL-6 receptor antagonist that has proven effective in treating systemic JIA. In a study on 56 patients between two and nineteen years old, treatment with tocilizumab resulted in sustained clinical improvement and had a favourable risk-benefit profile [49].

Abatacept and atlizumab are among the biological preparations that are currently in the clinical trial phase. Abatacept is a fusion protein that blocks the activation of T lymphocytes. Atlizumab is an IL-6 receptor antagonist [46].

Growth hormone is also being evaluated for use in children with JIA who have received long-term corticosteroid treatment. In one study, regular administration of growth hormone over several years improved growth rate, although the effect on terminal body height was less than expected. There was also an increase in serum IGF-1 and IGF binding protein levels, and a reduction in the proportion of adipose tissue [10].

In another study, growth hormone was administered to pre-pubescent children. The children were then observed for four years, during which time growth rate was significantly improved. Treatment was more effective in children with milder symptoms than in children with more active forms of the disease [50].

The major disadvantage of treatment with growth hormone is an increased risk of neoplastic disorders and scoliosis [41]. The exorbitant cost of treatment also limits its general use in minimizing growth retardation in children with JIA [8].

\section{Conclusions}

At the present time, the most effective way to reduce growth retardation in children with $\mathrm{IA}$ is to control inflammation with the help of currently available drugs, while reducing the duration and dosage of treatment with corticosteroids. It is also important to regularly monitor physical development. Further improvements to the treatment protocol depend on continued interdisciplinary research involving paediatricians, rheumatologists and clinical anthropologists.

\section{References}

1. Petty RE, Southwood TR, Baum J, et al. Revision of the proposed classification criteria of juvenile idiopathic arthritis: Durban, 1997. J Rheumatol 1998; 25: 1991-4.

2. Andersson Gäre B. Juvenile arthritis - who gets it, where and when: a review of current data on incidence and prevalence. Clin Exp Rheumatol 1999; 17: 367-74.

3. Romicka AM, Musiej-Nowakowska E, Szymańska-Jagiełło W. Juvenile idiopathic arthritis - clinical manifestations, diagnostic and management. Stand Med 2005; 1: 1434-9.

4. Petty RE, Southwood TR, Manners P, et al. International League of Associations for Rheumatology classification of juvenile idiopathic arthritis: second revision, Edmonton, 2001. J Rheumatol 2004; 31: 390-2.

5. Petty RE. Classifications of childhood arthritis: a work in progress. Baillieres Clin Rheumatol 1998; 12: 181-90.

6. Borchers AT, Selmi C, Cheema G, Keen CL, Shonfeld Y, Gershwin ME. Juvenile idiopathic arthritis. Autoimmun Rev 2006; 5: 279-98.

7. Wang SJ, Yang YH, Lin YT, Yang CM, Chiang BL. Attained adult height in juvenile rheumatoid arthritis with or without corticosteroid treatment. Clin Rheumatol 2002; 21: 363-8.

8. Simon D, Czernichow P. Arthrites juveniles et croissancie staturoponderale. Rev Rheum 2003; 70: 511-6.

9. Zak M, Müller J, Karup Pedersen F. Final height, armspan, subischial leg length and body proportions in juvenile chronic arthritis. A long-term follow-up study. Horm Res 1999; 52: 80-5.

10. Simon D, Lucidarme N, Prieur AM, Ruiz JC, Czernichow P. Treatment of growth failure in juvenile chronic arthritis. Horm Res 2002; 58 Suppl 1: 28-32.

11. Saha MT, Verronen P, Laipalla P, Lenko HL. Growth of prepubertal children with juvenile chronic arthritis. Acta Paediatr 1999; 88: 724-8.

12. Gołębiowska M, Brózik H, Chlebna-Sokół D, et al. Physical development and physical fitness in children with juvenile chronic arthritis (JCA). Reumatologia 1993; 31: 418-29.

13. Umławska W, Prusek-Dudkiewicz A. Short stature of children suffering from certain chronic diseases. Endokrynol Diabet Chor Przem Mat Wieku Rozwoj 2007; 13: 135-8. 
14. Valta H, Lahdenne P, Jalanko H, Aalto K, Mäkitie O. Bone health and growth in glucocorticoid-treated patients with juvenile idiopathic arthritis. J Rheumatol 2007; 34: 831-6.

15. Mainardi GL, Saleri R, Tamanini C, Baratta M. Effects of interleukin-1-beta, interleukin-6 and tumor necrosis factoralpha alone or in association with hexarelin or galanin, on growth hormone gene expression and growth hormone release from pig pituitary cells. Horm Res 2002; 58: 180-6.

16. Mårtensson K, Chrysis D, Sävendahl L.Interleukin-1-beta and TNF-alpha act in synergy to inhibit longitudinal growth in fetal rat metatarsal bones. J Bone Miner Res 2007; 19: 1805-12.

17. MacRae VE, Farquharson C, Ahmed SF. The restricted potential for recovery of growth plate chondrogenesis and longitudinal bone growth following exposure to proinflammatory cytokines. J Endocrinol 2006; 189: 319-28.

18. Wilkinson RH, Weissman BN. Arthritis in children. Radiol Clin North Am 1988; 26: 1247-65.

19. Simon S, Whiffen J, Shapiro F. Leg-length discrepancies in monoarticular and pauciarticular juvenile rheumatoid arthritis. J Bone Joint Surg Am 1981; 63A: 209-15.

20. Vostrejs M, Hollister JR. Muscle atrophy and leg length discrepancies in pauciarticular juvenile rheumatoid arthritis. Am J Dis Child 1988; 142: 343-5.

21. Bujnowski T. Evaluation of maximal physical fitness in children with juvenile chronic arthritis. Reumatologia 1997; 35: 51-61.

22. Hochberg Z. Mechanisms of steroid impairment of growth. Horm Res 2002; 58 Suppl 1: 33-8.

23. Klaus G, Jux C, Fernandez P, Rodriguez J, Himmele R, Mehls O. Suppression of growth plate chondrocyte proliferation by corticosteroids. Pediatr Nephrol 2000; 14: 612-5.

24. Ahmed SF, Tucker P, Mushtaq T, Wallace AM, Williams DM, Hughes IA. Short-term effects on linear growth and bone turnover in children randomized to receive prednisolone or dexamethasone. Clin Endocrinol 2002; 57: 185-91.

25. Simon D, Fernando C, Czernichow P, Prieur AM. Linear growth and final height in patients with systemic juvenile idiopathic arthritis treated with longterm glucocorticoids. J Rheumatol 2002; 29: 1296-300.

26. Roubenoff R, Roubenoff RA, Cannon JG, et al. Rheumatoid cachexia: cytokine-driven hypermetabolism accompanying reduced body cell mass in chronic inflammation. J Clin Invest 1994; 93: 2379-86.

27. Cleary AG, Lancaster GA, Annan F, Sills JA, Davidson JE. Nutritional impairment in juvenile chronic arthritis. Rheumatology 2004; 43: 1569-73.

28. Fukuda W, Yamazaki T, Akaogi T, et al. Malnutrition and disease progression in patients with rheumatoid arthritis. Med Rheumatol 2005; 15: 104-7.

29. Lepore L, Martelossi S, Pennesi M, et al. Prevalence of celiac disease in patients with juvenile chronic arthritis. J Pediatr 1996; 129: 311-3.

30. Argente J. Diagnosis of late puberty. Horm Res 1999; 51: 95-100.

31. Ballinger AB, Savage MO, Sanderson IR. Delayed puberty associated with inflammatory bowel disease. Pediatr Res 2003; 53: 205-10.

32. Alfredo M. Relationship between delayed menarche and bone mineralization in patients affected by juvenile idiopathic arthritis (JIA). J Clin Dens 2006; 9: 341.

33. Woźniak S. Rheumatoid arthritis - peculiarity in children. Ped Prakt 1998; 6: 13-6.
34. Ostensen M, Almberg K, Koksvik HS. Sex, reproduction, and gynecological disease in young adults with a history of juvenile chronic arthritis. J Rheumatol 2000; 27: 1783-7.

35. Huppertz HI, Tschammler A, Horwitz AE, Schwab KO. Intraarticular corticosteroids for chronic arthritis in children: Efficacy and effect on cartilage and growth. J Pediatr 1995; 127: 317-21.

36. Sherry DD, Stein LD, Reed AM, Schonberg LE, Kredich WM. Prevention of leg length discrepancy in young children with pauciarticular juvenile rheumatoid arthritis by treatment with intraarticular steroids. Arthritis Rheum 1999; 42: 2330-4.

37. Murray KJ, Lovell DJ. Advanced therapy for juvenile arthritis. Best Pract Res Clin Rheumatol 2002; 16: 361-78.

38. Cahill AM, Cho SS, Baskin KM, et al. Benefit of fluoroscopically guided intraarticular, long-acting corticosteroid injection for subtalar arthritis in juvenile idiopathic arthritis. Pediatr Radiol 2007; 37: 544-8.

39. Chedeville G, Quartier P, Miranda M, Brauner R, Prieur AM. Improvements in growth parameters in children with juvenile idiopathic arthritis associated with the effect of methotrexate on disease activity. Joint Bone Spine 2005; 72: 392-6.

40. Halle F, Prieur AM. Evaluation of methotrexate in the treatment of juvenile chronic arthritis according to the subtype. Clin Exp Rheumatol 1991; 9: 297-302.

41. Cassidy JT, Petty RE. Textbook of Pediatric Rheumatology. $4^{\text {th }}$ ed. London. W.B. Saunders Co, 2001.

42. Qartier P. When should we use TNF antagonists in children with rheumatic disease? Joint Bone Spine 2007; 74: 1-3.

43. Haraoui B. Differentiating the efficacy of the tumor necrosis factor inhibitors. Sem Arthritis Rheum 2005; 34 (5 Suppl 1): 7-11.

44. Vojvodich PF, Hansen JB, Andersson U, Sävendahl L, Hagelberg S. Etanercept treatment improves longitudinal growth prepubertal children with juvenile idiopathic arthritis. J Rheumatol 2007; 34: 2481-5.

45. Wallace CA. Current management of juvenile idiopathic arthritis. Best Pract Res Clin Rheumatol 2006; 20: 279-300.

46. Passo M. Emerging therapies in juvenile rheumatoid/ idiopathic arthritis. Curr Probl Pediatr Adolesc Health Care 2006; 36: 97-103.

47. Lovell DJ, Ruperto N, Goodman S, et al. Adalimumab with or without methotrexate in juvenile rheumatoid arthritis. N Engl J Med 2008; 359: 810-20.

48. Irigoyen P, Olson J, Hom C, et al. Treatment of systemic onset juvenile rheumatoid arthritis with anakinra. Arthritis Rheum 2004; 50: S437-8.

49. Yokota S, Imagawa T, Mori M, et al. Efficacy and safety of tocilizumab in patients with systemic-onset juvenile idiopathic arthritis: a randomized, double-blind, placebocontrolled, withdrawal phase III trial. Lancet 2008; 371: 998-1006.

50. Bechtold S, Ripperger P, Häfner R, Said E, Schwarz HP. Growth hormone improves height in patients with juvenile idiopathic arthritis: 4-year data of controlled study. J Pediatr 2003; 43: 512-9. 